\title{
Deformation behavior of 7050 aluminum alloy panels with variable thickness by shot peen forming
}

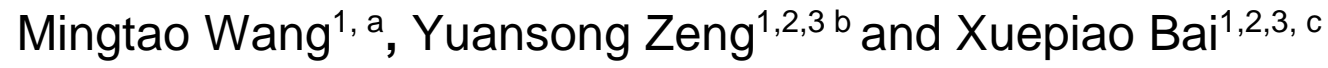 \\ ${ }^{1}$ AVIC Manufacturing Technology Institute, Beijing, China \\ ${ }^{2}$ Aeronautical Key Laboratory for Plastic Forming Technologies, Beijing, China \\ ${ }^{3}$ BeiJing Key Laboratory of digital plasticity forming technology and Equipment, Beijing, China \\ amartinthomaswang@163.com, byszeng@hotmail.com, cbaixp@163.com
}

\begin{abstract}
Keywords: Shot peen forming; 7050 aluminium alloy; Radius of curvature; Orthogonal experimental Abstract. Shot peen forming is an effective plastic forming method for integral panels with variable thickness used in aeronautical industry. 7050 aluminum alloy flat plates and 3-stiffeners panel were peen formed. The deformation behavior of those workpieces was investigated. The results reveal that the contribution of factors on plate deformation is in following order: thickness, air pressure and moving velocity of workpiece. Moreover, the regression formula about the quantitative relationship between radius of curvature and each factor has been established. Furthermore, the chordwise peen formed deformation of panel with typical structure is basic consistent with the regression formula which could afford some reference to shot peen forming future single shape panels with different thickness.
\end{abstract}

\section{Introduction}

Shot peen forming is a metal plastic forming process which is widely applied in aeronautical industry. It has many advantages: firstly, panels can be deformed without forming moulds; secondly, it has good adaptability to the panel length; thirdly, it is provided with the potentiality of prolonging the fatigue life [1]. Because of these advantages, shot peen forming is taking the place of traditional bending forming for processing the integral panel of large aircraft, such as the wing panel or fuselage [2]. The integral panel of large aircraft has complex shape and internal structure such as integral stiffeners. The large wing integral panels with stiffeners are likely to replace the multiple panels which are traditional splice joined with extruded sections in order to reduce the aircraft weight [3]. However, the stiffeners make the panels be more rigid. Besides, the thickness of the panels is variable. As a result, panels will be difficult to be formed accurately.

A considerable amount of research on the shot peen forming has been done during the last decade. Some researchers such as Gariepy et al. [4] investigated the influence of the rolling direction orientation with respect to the sample for aluminum alloy 2024-T3 specimens. C.Russig et al. [5] researched the shot peen forming of fiber metal laminates on the example of GLARE which is used in the fuselage components for the Airbus A380. Miao [6] et al. discussed the quantitative relationships between the prebending moment and the resulting arc heights of narrow strips and square strips.

However, those papers do not provide much attention to the variable thickness panels with stiffeners formed by shot peen forming. Therefore, the shot peen forming experiments were conducted based on 7050 aluminum alloy panel in this paper. The relationships among the forming curvature, shot peen forming parameters and the thickness have been established. After that, 3-stiffeners variable thickness panel has been formed in order to verify the quantitative relationships of this paper. The results could afford some basic reference to shot peen forming panels with stiffeners of future aircrafts. 


\section{Materials}

Material studied in this work was 7050 aluminum alloy whose mechanical characteristics are listed in Table 1. The workpieces were flat plates whose length was $400 \mathrm{~mm}$ and width was $300 \mathrm{~mm}$. The confirmatory test workpiece was 3-stiffeners panel whose dimension is shown in Fig.1. The thickness of panel skin was $4 \mathrm{~mm}$ or $2.5 \mathrm{~mm}$.

Table 1. Mechanical characteristics of 7050 aluminum alloys.

\begin{tabular}{lll}
\hline $\begin{array}{l}\text { Elastic } \\
\text { Modulus } \\
(\mathrm{GPa})\end{array}$ & $\begin{array}{l}\text { Yield } \\
\text { Strength } \\
(\mathrm{MPa})\end{array}$ & $\begin{array}{l}\text { Tensile } \\
\text { Strength } \\
(\mathrm{MPa})\end{array}$ \\
\hline 71.7 & 469 & 524 \\
\hline
\end{tabular}
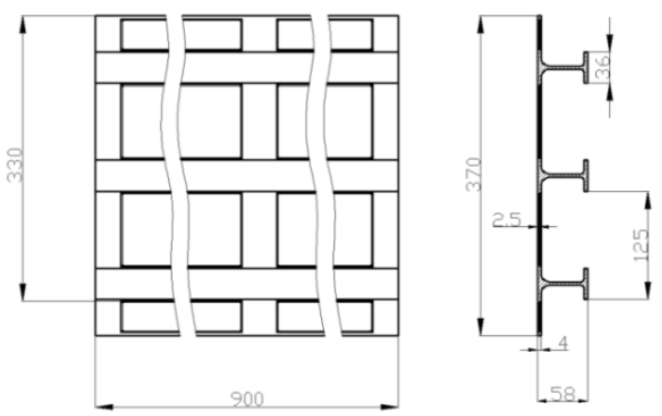

Fig. 1. Dimension of the 3-stiffeners panel.

\section{Method}

\section{Experimental method for shot peen forming flat plate workpiece}

The flat plate will be bent towards both chordwise and spanwise directions after shot peen forming. This paper was focused on the chordwise bending, so the peening path was the center line along spanwise direction, as shown in Fig.2.

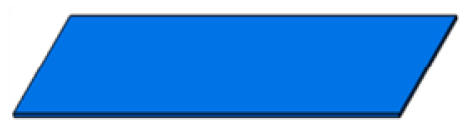

Before SPF

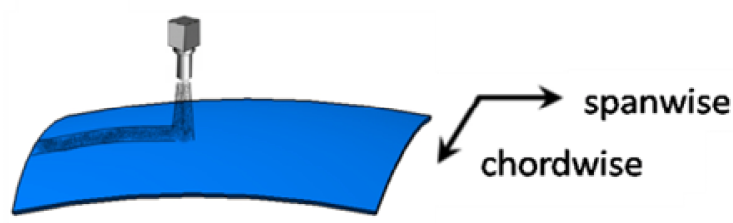

After SPF

Fig. 2. Peening path.

In order to set up the quantitative relationship among the chordwise curvature of workpiece, shot peen forming parameters and the thickness, an orthogonal shot peen forming experiment was designed in which there were three factors. Those were peening air pressure which represents impacting energy by shots, moving velocity of workpiece which reflects the peening coverage and the thickness of workpiece. Each factor had three levels thus there would be nine workpieces. In this orthogonal experiment, contribution of factors to the bent curvature could be analyzed by regression equation.

Three levels of each factor were defined in Table 2. The thickness of workpiece is from $2 \mathrm{~mm}$ to $6 \mathrm{~mm}$. Other processing parameters of shot peen forming were as follows: diameter of shot $\mathrm{D}=0.58 \mathrm{~mm}$, mass flow $\mathrm{Q}=6 \mathrm{Kg} / \mathrm{min}$, nozzle distance $\mathrm{L}=400 \mathrm{~mm}$. The arc height in the center of each workpiece was measured along chordwise direction after shot peen forming. The chordwise radius of curvature could be calculated by the arc height according to geometry. 
Table 2. Three levels of each factor.

\begin{tabular}{llll}
\hline $\begin{array}{l}\text { Workpieces } \\
\text { number }\end{array}$ & $\begin{array}{l}\text { Air } \\
\text { pressure } \\
(\mathrm{MPa})\end{array}$ & $\begin{array}{l}\text { Moving } \\
\text { velocity of } \\
\text { workpieces } \\
(\mathrm{mm} / \mathrm{min})\end{array}$ & $\begin{array}{l}\text { Thickness } \\
(\mathrm{mm})\end{array}$ \\
\hline PB-1 & 0.2 & 8000 & 2 \\
PB-2 & 0.2 & 10000 & 4 \\
PB-3 & 0.2 & 12000 & 6 \\
PB-4 & 0.3 & 8000 & 4 \\
PB-5 & 0.3 & 10000 & 6 \\
PB-6 & 0.3 & 12000 & 2 \\
PB-7 & 0.4 & 8000 & 6 \\
PB-8 & 0.4 & 10000 & 2 \\
PB-9 & 0.4 & 12000 & 4 \\
\hline
\end{tabular}

\section{Experimental method for shot peen forming 3-stiffeners panel workpiece}

In order to verify the deformation behavior between the shot peen forming parameters and chordwise curvature, 3-stiffeners panel with variable thickness was shot peen formed, as shown in Fig.3. The dimension and structure of 3-stiffeners panel were designed from practical aircraft wing panel. The stiffeners will make panel be hardly deformed towards spanwise if the stiffeners are not shot peened. As a result, the peen area was only the exterior surface of panel skin. Five parallel peening paths were along the spanwise direction. The shot peen forming parameters were listed in Table 3. Shot diameter, mass flow and nozzle distance were the same with orthogonal experiment.

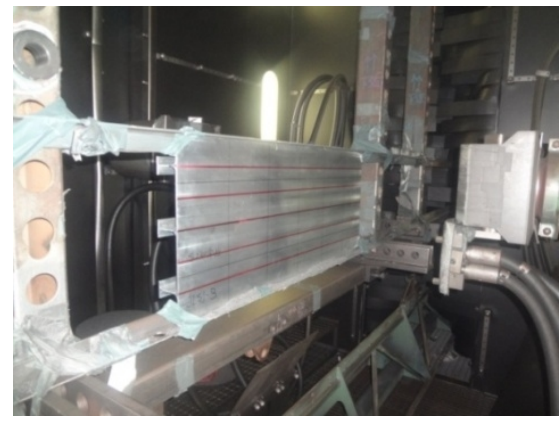

Fig. 3. Shot peen forming 3-stiffeners panel.

Table 3. Shot peen forming parameters of 3-stiffeners panel.

\begin{tabular}{lllll}
\hline $\begin{array}{l}\text { Shot } \\
\text { diameter } \\
(\mathrm{mm})\end{array}$ & $\begin{array}{l}\text { Air } \\
\text { pressure } \\
(\mathrm{MPa})\end{array}$ & $\begin{array}{l}\text { Moving } \\
\text { velocity of } \\
\text { workpieces } \\
(\mathrm{mm} / \mathrm{min})\end{array}$ & $\begin{array}{l}\text { Mass flow } \\
(\mathrm{kg} / \mathrm{min})\end{array}$ & $\begin{array}{l}\text { Nozzle } \\
\text { distance } \\
(\mathrm{mm})\end{array}$ \\
\hline 0.58 & 0.3 & 10000 & 6 & 400 \\
\hline
\end{tabular}

\section{Results and discussion}

\section{Results of shot peen forming orthogonal experiment}

Nine 7050 aluminum alloy flat plates were all spherically bent towards exterior panel-skins after shot peen forming. The deformation degree could be reflected by radii of curvature which were illustrated in Table 4. It can be seen that the radii of curvature of chordwise were from $492 \mathrm{~mm}$ to $7767 \mathrm{~mm}$ while that of spanwise were from $8988 \mathrm{~mm}$ to $40000 \mathrm{~mm}$. That meant spanwise deformation of workpiece was less than the chordwise deformation. The ratio of them was from $5.3 \%$ to $30.9 \%$. These results demonstrated that the surface materials would be stretched all around after impacting by 
shots. There would be residual compressive stress in the top surface while there would be tensile stress in the middle of material. The self-balancing of inner residual stress made the plate bend towards two directions. However, the bending degree along the peening path was less than that perpendicular the peening path. The results could afford some basic reference to shot peen forming integral panels designing. In order to acquire more deformation in designated direction, the direction of peening path should be designed suitably.

Table 4. Radius of curvature after shot peen forming.

\begin{tabular}{llll}
\hline \multirow{2}{*}{$\begin{array}{l}\text { Workpieces } \\
\text { number }\end{array}$} & \multicolumn{3}{l}{ Radius of curvature/mm } \\
\cline { 2 - 4 } & chordwise & spanwise & chordwise/spanwise \\
\hline PB-1 & 705 & 10666 & $6.6 \%$ \\
PB-2 & 3265 & 19512 & $16.7 \%$ \\
PB-3 & 7767 & 40000 & $19.4 \%$ \\
PB-4 & 2174 & 11267 & $19.3 \%$ \\
PB-5 & 4848 & 15686 & $30.9 \%$ \\
PB-6 & 564 & 10666 & $5.3 \%$ \\
PB-7 & 3902 & 20512 & $19.0 \%$ \\
PB-8 & 492 & 8988 & $5.5 \%$ \\
PB-9 & 1990 & 10666 & $18.7 \%$ \\
\hline
\end{tabular}

In the orthogonal experiment, the range of each factor represents the degree of contribution on the radii of curvature. Fig. 4 illustrates the three ranges contrast bars after the different shot peen forming. It demonstrates that the maximum and minimum extent of influence on chordwise bending curvature is respectively thickness and moving velocity of workpiece.

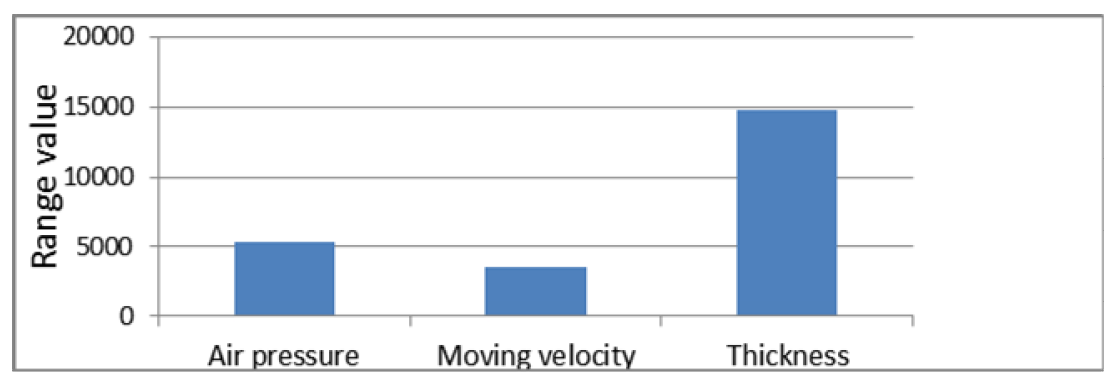

Fig. 4. The range value of each factor.

The regression analysis of the radius of curvature $R$ was performed in order to obtain quantitative relation between $R$ and each factor. According to the shot peen forming rules, $R$ will increase when moving velocity of workpiece and panel thickness increase, while $R$ will decrease when air pressure increase. As a result, $R$ could be expressed as Eq. (1),

$$
R=K \frac{V^{m} t^{\alpha}}{P^{n}}
$$

where $P$ is air pressure, $V$ is moving velocity of workpiece, $t$ is thickness.

Two sides of Eq. (1) were logarithmic transformed, as shown in Eq. (2),

$$
\ln R=\ln K+m \ln V+\alpha \ln t-n \ln P,
$$

Defining:

$$
Y=\ln R, \quad b_{0}=\ln K, X_{1}=\ln V, X_{2}=\ln t, X_{3}=\ln P,
$$


Eq. (2) was transformed to Eq. (3),

$$
Y=b_{0}+m X_{1}+\alpha X_{2}-n X_{3}
$$

Putting nine groups of $Y, X_{1}, X_{2}$ and $X_{3}$ into Eq. (3), the coefficients were calculated using multiple linear regression method. Eq. (4) shows the equation about the radius of curvature $R$, which reflects the deformation of workpiece in chordwise direction.

$$
R=3.197 \frac{V^{0.3129} t^{2.01431}}{P^{0.75285}}
$$

Putting three factor values of each workpiece into above equation, the chordwise radius of curvature was respectively calculated as fitted value. Fig.5 shows nine workpieces' fitted values and their corresponding experiment values. It shows that the predicted value resulted from math model approximates actual value.

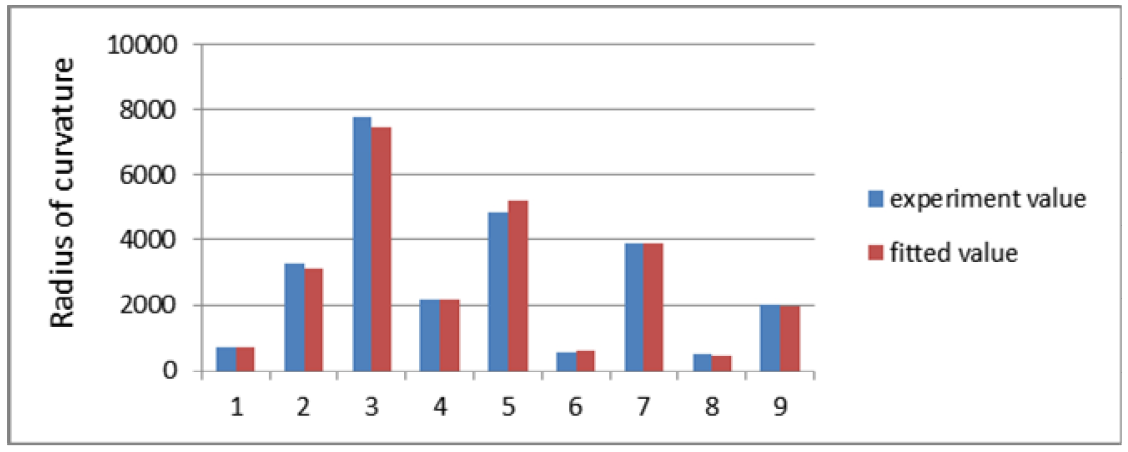

Fig. 5. Contrast between experiment value and fitted value.

\section{Results of shot peen forming 3-stiffeners panel experiment}

Fig.6 shows the deformation of 3-stiffeners panel after shot peen forming. It displays that the panel skin have convex bend along chordwise direction. However, there was nearly no deformation along spanwise direction because of the restriction of rigid stiffeners. The radii of curvature of 15 points showed in Fig. 7 were measured. It showed that the radii of curvature were from $1139 \mathrm{~mm}$ to $1552 \mathrm{~mm}$. The average of 5 points in L2 was larger than that L1 or L3. This because the skin material near L2 was restricted by two stiffeners, while that near L1 or L3 was restricted by only one stiffener. Under the same shot peen forming condition, the skin near L2 was harder to be deformed.

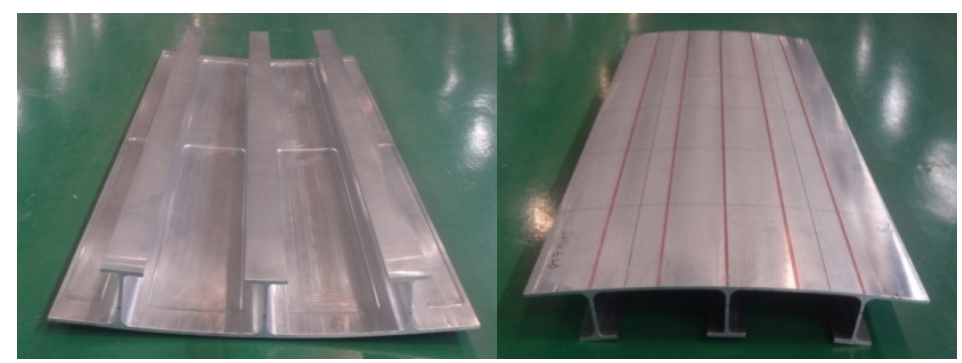

Fig. 6. 3-stiffeners panel after shot peen forming. 


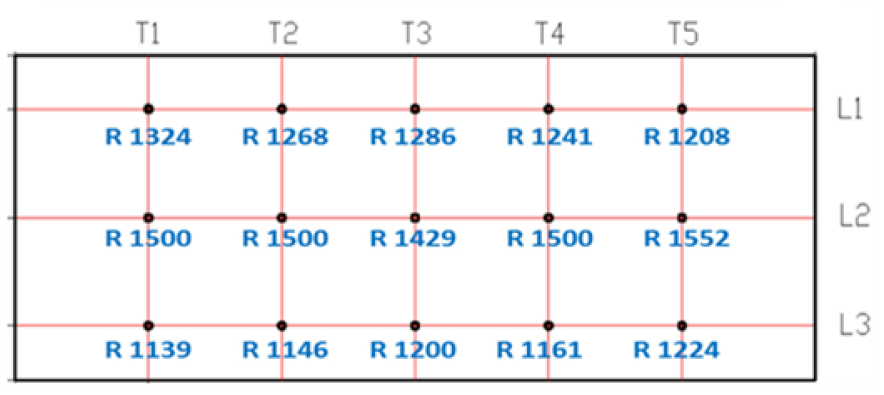

Fig. 7. Chordwise radius of curvature after shot peen forming.

Putting the values of air pressure, moving velocity of workpiece and thickness of the 3-stiffener panel into the regression equation, the chordwise radii of curvature were calculated. They were $2305 \mathrm{~mm}$ or $894.5 \mathrm{~mm}$ when the thickness was $4 \mathrm{~mm}$ or $2.5 \mathrm{~mm}$. From Fig.7, all the radii of curvature of the external skin in the panel were in the range from $894.5 \mathrm{~mm}$ to $2305 \mathrm{~mm}$. This result shows that regression equation could afford some reference to the shot peen forming parameters of single cylinder shape panels with non-deformed stiffeners.

\section{Conclusions}

In this paper, the deformation behavior of 7050 aluminum alloy flat plates after shot peen forming have been investigated in orthogonal experiment. Besides, one 3-stiffeners panel with different thickness has been formed to single cylinder shape. The following conclusions could be drawn:

(1) When the plate panel is shot peen formed, the deformation degree perpendicular the peening path was larger than that parallel the peening path.

(2) The regression equation about the quantifiable relation between radius of curvature and shot peen forming parameters has been established. The effectiveness of factor on chordwise deformation degree of flat plate is in following order: thickness, air pressure and moving velocity of workpiece, if other parameters are not changing.

(3) Predicting the chordwise deformation degree of single curvature panels with non-deformed stiffeners could refer to the regression equation.

\section{Acknowledgements}

This paper is financial supported by National Key R \& D Program of China (2017YFB0306303)

\section{References}

[1] M.Kulkarni, John A.Schey, Douglas V.Badger. Investigation of shot peening as a forming process for aircraft wing skins, American society for metals, 1(4)(1981)34-44.

[2] Takeshi Yamada, Takayuki Takahashi, et al. Development of shot peening for wing integral skin for continental business jets, Technical Review, 39(2)(2002)57-61.

[3] A Frises. KSA develops new automated peen forming for wing skins, The shot peener, (2006)16-17.

[4] A. Gariépy, S. Larose, C. Perron, et al. On the effect of the orientation of sheet rolling direction in shot peen forming, Journal of Materials Processing Technology, 213(2013)926-938.

[5] C. Russig, M. Bambach, G .Hirt, N. Holtmann. Shot peen forming of fiber metal laminates on the example of GLARE, Int J Mater Form (2013)

[6] H.Y. Miao, D. Demers, S. Larose et al. Experimental study of shot peening and stress peen forming, Journal of Materials Processing Technology, 210(2010)2089-2102 